\title{
ASYMMETRIC WARFARE: EXPERIENCES, PERSPECTIVES, INKLING AND CHALLENGES WITH A FOCUS ON ZIMBABWE
}

\section{Raymond Mharapara ${ }^{1}$, Lucky Bassie Bangidza ${ }^{2}$ and Steven \\ Gwekwerere $^{3}$}

\section{Introduction}

The world has become dependent on interdependence and globalization because the processes that promote worldwide exchanges of national and cultural resources are generating further interdependence of economic and cultural activities (Robertson 2000). Therefore, one can state that religion and culture are no longer only important ingredients of civilization, but potential causes of division and isolation. A good example is that only a few Muslim governments overtly supported Saddam Hussein, many Arab States privately cheered him on, and he was highly popular among large sections of Arab populaces. When invoking parallels and using them as strong rallying points, Muslims contrasted Western actions against Iraq with the West's failure to protect Bosnia against Serbs and also to impose sanctions on Israel for violating UN resolutions (Huntington 2006, 447). As a result, differences in power and struggles for

\footnotetext{
${ }^{1}$ Mharapara is Director of the National Defence College (NDC) under the Institute of Strategic Research and Analysis (ISRA).

2 Bangidza is a Research/Facilitator at National Defence College under the Institute of Strategic Research Analysis (ISRA). A PhD student at the University of Zimbabwe. E-mail: lbbangidza@yahoo.com.

${ }^{3}$ Gwekewrere is Colonel of General Staff (GS) in the Zimbabwe National Army Headquarters.
} 
military, economic and institutional power are now sources of conflict between the West and other civilisations. Consequently, it could be assumed that fundamental economic reforms give rise to necessary political transformation.

During the Cold War, the concept of "collective security" gained popularity and significance when it meant balancing the military strength of the United States and its allies against, on the other side, Soviet Union and countries of the Eastern Bloc (Shils 1955, 105). Now that the definition refers to those non-Western countries seeking to match and/or torpedo the balance with Western nations, it is becoming increasingly clear that any state not towing U.S. path is classified an enemy. As there is asymmetric threat to Zimbabwe, the nation should however not lose sight of the fact that the presence of a threat could develop rapidly and form very dynamic circumstances. Just a misguided or misplaced machine gun could turn out to be a runaway gun or a statement to the media casting aspersions on a certain civilisation and/or religion and, therefore, could trigger such an immediate threat.

Likewise, the Zimbabwean government should strengthen processes that constantly keep at a distance the prospects of asymmetric threat. Zimbabwe should embrace collective security concept with neighboring states. Morgenthau $(1954,126)$ asserts that such collective security organisations typically require "that all nations come to the aid of a victim of aggression with all means necessary." A successful response would call for an approach that leverages the partnerships with diverse non-government actors and wields a range of disciplines, including communication, law enforcement, business and academy. It could be easily argued that soft power should have more precedence than military solutions because even as a state amass a high-tech arsenal, asymmetric threat does not necessarily allows its successful use. United States, as a hegemon, is being subtly challenged by multiple states that have strengthened their economies, enhanced their militaries, and gained increased credibility. The danger is that these rising powers and non-state actors are increasingly gaining or achieving parity and the ability to assert coveted local and regional hegemony.

To mitigate asymmetric threat there should be a grand strategy to reduce poverty and its accompanying scarcity of resources; water, food, health, employment and energy because this threat is grounded in a clash of civilization. To date we have not heard any asymmetric attacks or disruptions 
on Chinese soil, which implies that China is correctly applying its soft power and hard power approach to international relations. All states aiming at attaining hegemony status like U.S. should learn not to alienate others due to civilization or religion differences, for to do so would be creating unnecessary enmity and foster fertile ground for asymmetry from non-state actors and extremist groups, external and internal. For that reason, defensive soft power serves to keep at bay adversarial preferences, attitudes, perspectives, objectives, and modes of behavior. The recent bombings in Boston, Massachusetts (2013) indicates and proves beyond doubt that U.S. hard power would never prevail over asymmetric attacks by non-state actors and extremist groups as long as global poverty, indifference to other civilisations and religions, and failed/failing states exist. Therefore, Zimbabwe must wake up to today's realities and employ soft power: the full range of tools at disposal, diplomatic, economic, political, legal, and cultural - picking the right tool, or a combination of tools, for each situation.

In order for any state, Zimbabwe included, to realistically keep extremism and asymmetric threat at bay, elements of soft power must be exploited. Nye, Jr. (2004) defines soft power as, "the ability to get what you want through attraction rather than coercion or payments. It arises from the attractiveness of a country's culture, political ideals, and policies". When a state's policies are perceived as legitimate and just in the eyes of others, that state's soft power is enhanced. In the view of many a state's foreign policy, in particular of those states viewed as outcasts by the USA, is inherently hegemonic and designed to superintend other civilisations, religion and culture. A befitting example is the U.S.' military invasion and attack on Iraq. The U.S. managed to remove a "tyrant" but dismally failed to resolve its vulnerability to terrorism and asymmetric threat. Conclusively, as long as any state prefers other means, especially hard power, than soft power to solving problems, disputes or quarrels in international relations, the scourge of terrorism and asymmetric threat would haunt it. 


\section{Asymmetric Challenges}

The concept of asymmetric straggle has been around the world for a long time, but has become a topical issue of recent. The defence setting has been considerably complicated in recent years by rise of what has become known as "asymmetric warfare threat". In his remarks to the graduating class of the US military academy West Point, President J F Kennedy (1962) observed that "there is another type of warfare new in its intensity, ancient in its origin. War by guerrillas, subversives, insurgents, assassins, war by ambush instead of combat, by infiltration instead of aggression, seeking victory by eroding and exhausting the enemy instead of engaging him... it preys on unrest".

Simply defined, Paul $(2005,5)$ observed that

(...) asymmetric warfare is a conflict between two sides, which have a large disparity in political, economic and military power. The weaker opponent may not necessarily be a nation and increasingly could be a group representing ethnic, religious or criminal interests.

It can be simply said that its aim therefore is to weaken political resolve rather than military power and attacks could be expected far from any conventional battlefield. In asymmetric warfare, fighting occurs on the economic, political, diplomatic, social and the military front when conducive. Therefor,e one can conclude that major weapon used by the stronger sides is mainly economic, political and diplomatic through the battle for the minds. The weaker sides in turn tend to resort to generally insurgent tactics to kill the mightier power's will to fight. Seethaler et al $(2013,117)$ observed that "information and communication technologies have emerged as one of the major weapons employed by both sides engaged in asymmetric warfare".

\section{Understanding Asymmetric Warfare}

Fagan and Munck $(2009,286)$ indicated that "asymmetric warfare is mostly characterised with the battle for the mind. Always associated with the weak, asymmetric warfare has changed its form because it no longer has defined objectives". Messinger $(2001,101)$ observes that "asymmetric warfare is more a reaction than a cause". Therefore, the definition of the 'weak' has also changed. 
In simplistic terms, strategy is made up battle for the minds. If it is the battle for the minds, the interaction often involves strategies and tactics outside the bounds of conventional warfare. Tsu (2003) stated that if you employ soldiers without sorting out the skilled and unskilled, the brave and the timid, you are bringing defeat on yourself. The contour of the land is an aid to an army; sizing up opponents to determine victory, assessing dangers and distances, are the proper course of action for military leaders. Those who do battle knowing these will win those who do battle without knowing these will lose.

Generally asymmetric warfare can be a conflict involving two states with unequal overall military and economic power resources and could be individuals, groups and communities. The obvious shortcomings of this definition are to confine wars to state actors when non-state actors such as alQaeda are involved in war against states not defined geographically, but as a diaspora entity. It can easily be concluded that al-Qaeda is not concerned about attacking the territory of the state alone, but also anything associated with the state in question across the globe. The other drawback is to perceive asymmetry in terms of "overall military and economic power" sidelining the potential effect of inequalities in political and social resources, which also play an equally important role in defining the degree of asymmetry between any opponents. Realising some of these deficiencies in defining asymmetric warfare, Hess and Orthmann (2012, 382) defined asymmetric warfare as "leveraging inferior tactical or operational strength against the vulnerabilities of a superior opponent to achieve disproportionate effect with the aim of undermining the opponents will in order to achieve asymmetric actors' strategic objectives."

Unfortunately this definition only sees the bigger nations as the victims and objects of asymmetric warfare, yet the reality, especially for us in the developing world, is that the bigger nations unleash their superior tactical or operational, as well as political, diplomatic, economic and social strength against the vulnerable or weaker nations. Their aim is to undermine the weaker nations in order to achieve their strategic objectives. Chinyamakobvu (2011, 108) observed that

the Zimbabwe Democracy Economic and Recovery Act (ZDERA), is a punitive sanction measure, imposing bill hastily passed by the American Congress in December 2001. Passed into law by President George W Bush, putting a blanket 
ban on all fresh financial lending to Zimbabwe and the rescheduling of its debts by International financial institutions such as, the IMF, World Bank and the African Development Bank of which the U.S. is a member.

This piece of legislation is precisely meant to achieve the strategic objectives of the U.S.' interests and their values.

This is obviously a lesson learnt from their adventures in the Vietnam, Iraqi wars and other campaigns where they used excessive and unnecessary force, but still incurred heavy casualties, much to the humiliation of their population back home. When an attack on Iraq was imminent in 1990 following the invasion of Kuwait by Iraq, Stroilov (2011, 103) described asymmetric warfare from the perspective of a weaker adversary by saying:

If you use pressure, we will deploy pressure and force. We know that you can harm us although we do not threaten you. However, we too can harm you. Everyone can cause harm according to their ability and their size. We cannot come all the way to you in the United States, but individual Arabs may reach you.

Therefore, it is clear that everyone, big or small, is equally worried about asymmetric warfare. In the realm of military affairs and national security, asymmetry is acting, organizing, and thinking differently than opponents in order to maximize one's own advantages, exploit an opponent's weaknesses, attain the initiative, or gain greater freedom of action. It can be political-strategic, military-strategic, operational, or a combination of these. It can entail different methods, technologies, values, organizations, time perspectives, or some combination of these. It can be short-term or long-term. It can be deliberate or by default. It can be discrete or pursued in conjunction with symmetric approaches. It can have both psychological and physical dimensions. The history of asymmetry in warfare can be traced back to the antiquities and origins of war. Smith $(2004,1)$ observed Sun Tzu in The Art of War saying that "all war is based on deception". This is based on strengths and weaknesses, which today we call the threat-response dynamic. Since the time of Sun Tzu, we have seen asymmetric approaches used in every conflict. 


\section{Significances of Asymmetric Warfare}

It is important to study asymmetric warfare since it might be waged upon us when we are not aware of it like what has been the case of Zimbabwe during the past 13 years. The war sometimes assumes violence as both acceptable, necessary and draws no distinction between military and civilian targets. The enemy could inflict mass causalities on a large scale. How many people died owing to lack of proper medical care during the last couple of years as a direct or indirect effect of the illegal sanctions imposed on Zimbabwe by the West? How many Zimbabweans were eaten by crocodiles and drowned in the Limpopo trying to cross into South Africa in search of greener pastures? How many were killed or maimed in political-related violence incidence including the notorious xenophobic attacks in the Republic of South Africa? Could all these have sacrificed their precious lives if there was no sanctions and Zimbabwe Democracy and Economic Recovery Act (ZIDERA) imposed by the U.S.?

Nevertheless, asymmetric warfare will not end at an appointed hour by signing of peace agreement or declaration of a ceasefire. The arrival of this day will not be apparent at the time, but will become ever clear as the absence of mass fatality and destruction of property diminishes. Therefore, it is important to study asymmetric warfare because it is now a factor of strategic significance. It poses great challenges to defence transformation. To answer the challenges requires a shift in paradigms.

\section{Patterns of Asymmetric Warfare}

The utmost problematic pebble dashing human development today is that society is losing deep human values - integrity, compassion and respect. The society is constantly faced with temptations to compromise ethics and take a short-cut road to riches. The desires for money, sex, power and fame often translate into corruption, lies, love-affairs or crime. A minute of pleasure leads to many years of suffering. And by valuing wealth above ethics we lose everything (Nematandani 2012). World politics is entering a new phase, where we seem to be returning to traditional rivalries between nation states and the decline of the nation state from the conflicting pulls of tribalism, interdependence and globalisation among others. The fundamental source of 
struggles in this new world will not be primarily ideological or economic as was during the cold war. The great divisions among mankind and the dominating source of conflict will be cultural. Nation states will remain the most powerful actors in world affairs, but the principal conflicts of global politics will occur between nations and groups of different civilisations. Therefore, the next pattern of conflict is the clash of civilisations as the battle lines. Is it a clash of civilisation or a clash of interests?

\section{Conflict between Civilisations}

Crothers and Lockhart $(2000,100)$ observed that the "conflict between civilizations will be the latest phase in the evolution of conflict in the modern world". Conflicts of the western world were largely among princes, emperors, absolute monarchs and constitutional monarchs attempting to expand their bureaucracies, their armies, their mercantilist economic strength and most important, the territory they ruled. In the process they created nation states, and, beginning with the French Revolution, the principal lines of conflicts were between nations rather than princesses, until the end of World War I. As a result of the Russian Revolution and the reaction against it, the conflict of nations yielded to the conflict of ideologies, first among communism, fascismNazism, liberal democracy and capitalism/ imperialism. During the Cold War, this latter conflict became embodied in the struggle between the two superpowers, neither of which a nation state in the classical sense defined more in terms of ideology.

These conflicts between princesses, nation states and ideologies were, for the West, primarily regarded as "the clash of civilisations or western civil wars". This was also true for the cold war and the earlier wars of the seventeenth to the nineteenth centuries. With the end of the Cold War, international politics moved out of its Western phase, and its centre-piece became the interaction between the west and among non-western civilisations. In the politics of civilisations, the people and governments of non-western civilisations no longer remain the objects of history as targets of western colonialism, but join the West as movers and shapers of history. 


\section{Nature of Civilisation}

During the Cold War, the world was divided into the first, the second and the third worlds. Those divisions are no longer relevant. It is far more meaningful now to group countries not in terms of their political or economic systems or in terms of their level of economic development but rather in terms of their culture and civilisation. Huntington $(2000,43)$ observes that "civilisation is a cultural entity. Villages, regions, ethnic groups, nationalities, religious groups, all have distinct cultures at different levels". The culture of a village in southern Zimbabwe may be different from that of a village in northern Zimbabwe, but both will share in common Zimbabwean culture that distinguishes them from Malawian villages. Huntington also observed that

European communities, in turn, will share cultural features that distinguish them from African, Arab or Chinese communities. Civilization is thus the highest cultural grouping of people and the broadest level of cultural identity people have, short of that which distinguishes humans from other species. It is defined both by common objective elements, such as language, history, religion, customs, institutions and by the subjective self-identification of people (Huntington 2000, 43).

People can and do redefine their identities and, as a result, the composition and boundaries of civilisations change. One can now put the onslaught of Britain and her allies, from Australia to the U.S., on Zimbabwe into context. They constitute the western civilisation.

Civilisations may involve a large number of people, as with China, or a very small number of people such as Swaziland a country in a womb of another country. Huntington (1993) says that

(...) a civilisation may include several nation states, as is the case with western and Islamic civilisations, or only one, as is the case with the Japanese civilisation. Civilisations obviously blend and overlap, and may include sub civilisations. Westerners tend to think of nation states as the principle actors in global affairs.

Westerners have been like that, however, for only a few centuries. But the broader reaches of human history have been the history of civilisations, development and progress. 


\section{Torn Countries}

In general, parliamentarians exercise their power and attitudes to the duty of representing the citizen's interests. Instead, in many cases, according to Santoni and Mair (2005),

(...) parliamentarians are interested in party political interests and discipline. At the individual level, the parliamentarians are often eager to remain in the good books of influential officials of both civilian and military decision-making bodies. They worry more about maintaining good relations with the President or Prime Minister rather than looking after those who elected them.

With such a scenario, it can be safely interpreted as asymmetric warfare by our own citizens, because of being partocratic than being nationalistic in approach. This is another form of dangerous warfare, sometimes more difficult to determine and define.

It can effortlessly be pointed out that states can just as systematically be disrupted and destroyed by internal challenges (at the sub-state or from the national level) as they can be by external forces. The Democratic Republic of the Congo (DRC) is a good example of domestic rebellion (such as the repeated secession attempts by Katanga during the 1960s), predatory governance (under Mobuto Sese Seko) and foreign invasion (by Uganda and Rwanda in 1998) - all three of which undermined national security. It could be easily said that the challenge in Africa today is that national security is equated with that of the governing elite - 'governing' in the interests of their own preservation and advancement, with limited provision of human security for their citizenry.

However, some countries have a fair degree of cultural homogeneity but are divided over whether their society belongs to one civilisation or another. These are torn countries. Their leaders typically wish to pursue a strategy and to make their countries member of the west, but the history, culture and traditions of their countries are non- western. Crothers and Lockhart (2000, 113) said that, "the most obvious and prototypical torn country is Turkey". Turkish leaders have defined Turkey as a modern, secular, western nation state, allying Turkey with the west in NATO. During the Gulf War, Turkey applied for membership in the European Community but elements in the Turkish society have supported an Islamic revival arguing that Turkey is basically a 
Middle Eastern Muslim society. The elite of the west also refuse to accept Turkey as part of the western society. In Crothers and Lockhart (2000, 13), one of the Turkey Presidents said that, "Turkey will not become a member of the European community and the real reason is that we are Muslim and they are Christian and they don't say that". Encouraged by the west, Turkey is making strenuous effort to carve out this new identity for itself.

\section{The Clash of Civilisations}

Civilisation identity will possibly increase its important in the future. Fox (2001) observed that "the world will be shaped mainly by interactions among seven or eight major civilisations and they are Western, Confucian (Chinese), Japanese, Islamic, Hindu, Slavic-orthodox, Buddhist and possibly African civilisation". Why will this be the case? Huntington (1993) pointed out that differences among civilisations are not only real; they are basic, clans taking care of their own. Civilisations are differentiated from each other by history, language, culture, tradition and most important religion. Hatem (2000) said that

(...) people of different civilisations have different views on the relations between God and man, the individual and the group, the citizen and the state, parents and children, husband and wife, as well as differing views of the relative importance of rights and responsibilities, liberty and authority, equality and hierarchy. These differences are the product of centuries and will not soon disappear. They are far more fundamental than differences among political ideologies. Differences do not necessarily mean conflict, and conflict does not necessarily mean violence.

Huntington (2002) said that, "over the centuries however, differences among civilisations have generated the most prolonged and the most violent conflicts". Does this idea attempt to explain the upheavals in the Middle East and North Africa?

In International Relations, the elaboration is on the theory of interdependence to break down boundaries and differences in order to enhance economic and social interactions. Huntington (1993) observed that, the world is becoming a smaller place and interactions between peoples of different 
civilisations increasing thus intensifying consciousness and awareness of differences between civilisations and commonalities within civilisations. A Mumanyika could be Mujindwi, Mugarwe, Mundau, Barwe, Manyika, in Manicaland, simply Samanyika in Harare, a Zimbabwean in Windhoek and an African in Beijing. Ulusoy (2004) observed that "the interactions among peoples of different civilisations therefore enhance the civilisation-consciousness of people and, in turn, invigorates differences and animosities stretching or thought to stretch back deep into history". Does this explain the Hutu Tutsi issue?

Huntington (1993) observed that economic modernisation and social change throughout the world are separating people from longstanding local identities and weaken the nation state as a source of identity. In much of the world, religion has moved in to fill this gap, often in the form of movements that are labelled fundamentalist. Such movements are found in Western Christianity, Judaism, Buddhism and Hinduism, as well as in Islam. General observation according to Huntington indicates that, in most countries and most religions, the people active in fundamentalist movements are young, collegeeducated, middle- class technicians, professionals and business persons. Does this explain the emergence of the Makandiwas, Pastor Chris, and Dr. Utaunashe groups in Zimbabwe?

Ritzer and Atalay (2010) observed that the growth of civilisation, consciousness in the west is at the peak of power, whilst there is a tendency of returning to the roots phenomenon occurring among non-western civilisations. Hence, increasingly we hear of the "Hindunisation" "Westernisation versus Russianisation in Russia". Does this explains the emerging alliances like Brazil, Russia, India, China and South Africa (BRICS) and the waning of the nonaligned movement? In the past, the elites of the Zimbabwean society were usually the people who were most involved with the west. They were educated at Oxford and trained at Sand Hurst, and absorbed western attitudes and values whilst the populace remained deeply imbued with or inspired by indigenous culture. There is need to de-westernise and indigenise the minds of the elites in Zimbabwe and at the same time that American cultures, styles and habits should not become more popular among the people. Does this explain the Look East Policy vs. Zhing Zhong mentality in Zimbabwe? 


\section{Multi-Dimensional Challenges}

Different nations understand asymmetric warfare differently and according to their environment. It can be concluded that for the British and Americans, asymmetric warfare is a multi-dimensional conflict which is fought simultaneously on the economic, political, diplomatic, social and sometimes concurrently on the military front. These are termed the instructions of power, commonly known for diplomatic (and political), information, military and economy. In Zimbabwe, the wanton destruction of anything considered to be "government property" in the run-up to the 2000 general election and 2002 presidential election was evidence of an economic front in asymmetric warfare. The defacing of road signs and destruction of basic structures like the rail, electric line, bus terminals and telecommunication lines appeared on the surface to be just other acts of civil disobedience, but that was the real face of asymmetric warfare on the economic front. The objective here was to exploit the weakness identified within the nation and use the local people to destroy their own economy. Zimbabweans were complicit with the destruction of the Zimbabwean economy between 2000 and 2008. The so-called captains of industry were steering the economy off course. An analysis of the situation in Zimbabwe during the period 2000-2008, shows that the country had been attacked on the economic front by the imposition of sanctions, ZDERA, economic sabotage, illegal money deals which resulted in what the Governor of the Reserve Bank of Zimbabwe DR Gono would call the casino economy in 2008 .

The flight of skilled labour to other countries, maladministration, hoarding of basic commodities, and closure of the production industry characterised that period and there is no classical economic theory which explains why the Zimbabwean Dollar would lose its value at such a rate. In the morning the exchange rate would be 1:15 million, by noon, it is 1:100 million. In all these activities, you will see that locals were the foot soldiers against their own economy, some knowingly but some specifically or specially recruited for that campaign against the Zimbabwean state. The conditions of the civil servants were and are still horrendous; the basic human approach was the target. The result was a shortage of nearly everything from the very sensitive things like sanitary pads, medicines etc. Our opponents then used these 
shortages as a reason to argue that Mugabe had lost all legitimacy to rule. Zimbabweans also executed field burials at 'Mbudzi' cemetery against our culture owing to fuel shortages, cash or both. Attacks on the political and diplomatic front capitalising on weakness or shortfalls, which were blown out of proportion and politically internationalised. In recent years and in many countries the focus has been on constitution making. What was the interest of the EU and its allies in Zimbabwean constitution making process?

\section{Terrorism and Insurgents}

While many terrorist actions are relatively low in technology, one should not assume that weak opponents would not have access to high technology. Perhaps the only characteristics of asymmetric warfare that can be stated with certitude are that it is applied suddenly and unexpectedly. Examples are 9/11, Bali, Kenya and Tanzania bombings, just to mention a few. Asymmetric approaches employ or affect one or more of the elements of national power (military, political, diplomatic, economic and information). Asymmetric warfare generally seek a major psychological impact, such as shock or confusion that affects an opponent's initiative, freedom of action or will. Asymmetric approaches often employ innovative, non-traditional tactics, weapons, or technologies and can be applied at all levels of warfare and across the spectrum of military operations. It is generally employed to achieve results disproportionate to invested effort.

Now that we have examined the characteristics, weapons, and forms of asymmetric warfare, how is it possible to protect or plan against an asymmetrical attack? The nature of the "threat-response dynamic" is to analyze all real and perceived threats and vulnerabilities to produce a counter measure or reinforcement to a vulnerability. It will never be possible to fully protect against an asymmetric attack, as there are limited resources and an almost infinite number of scenarios to be considered. The best that any state or nonstate can hope for is that intelligence is leveraged in such a way to create a list of most likely scenarios to guard against. It is a vicious circle, for the act of analysis and response constantly produces additional threats and vulnerabilities as resources are shifted to compensate for perceived or real threats and vulnerabilities. At the core of this dynamic is intelligence; not the quantity of 
intelligence, but the quality of both the data and the analysis. Any state or nonstate that wishes to be successful in countering asymmetric threats or attacks must have a productive and accurate intelligence system in place. This intelligence system should be responsible for the collection, dissemination, and analysis of data in response to balanced priorities set by the states or organisations leadership. The leadership can be either centralised or decentralised from the perspective of the intelligence system.

In addition to a normal collection, analysis and reporting process, an alerting system based on the concept of "management by exception" must be put in place and tied to early warning systems, which are designed to monitor changes in antagonist activities and escalate reports via a separate and distinct chain of command. Only with accurate, timely, and complete intelligence can an organization, state or non-state, hope to protect itself against asymmetric threats.

\section{Conclusion}

Asymmetric warfare is not something new, since wars have never been fought by equal opponents. Enemies will always have some political, social and economic asymmetry, or in terms of overall military capability. Asymmetric warfare's objective is to weaken political resolve rather than military power through attacks away from any conventional battlefield. It is fought on the economic, political, diplomatic, social and military fronts when it is conducted. It is the battle for the minds, and, therefore, tactics vary constantly, since each application is unique. It is important to study asymmetric warfare to avoid surprises. It is a war of ideas where the centre of gravity lies in the hearts and minds.

Villages, regions, ethnic groups, nationalities, religious groups, they all have distinct cultures at different levels. A civilisation is thus the highest cultural grouping of people and the broadest level of cultural identity. Civilizational identity will be increasingly important in the future, and future conflicts are likely to be civilisation-oriented as peoples scramble for resources.

Different nations understand asymmetric warfare in distinct ways. Weaker sides, however, could use other tactics - including terrorism - to 
achieve the same goals. Asymmetric approaches employ or affect one or more of the elements of national power, besides seeking a major psychological impact. Innovative, non-traditional tactics, weapons, or technologies are applied at all levels, from strategy down to tactics, in order to achieve results disproportionate to invested effort. It is a mental battle, exploiting your strength against an enemy's weakness and recognising that all areas of human endeavour are part of the battleground and counterbalance any lack of conventional force. It cuts across all human spectrums: political, economic and social. Asymmetric warfare can hit anytime, anything, anywhere. It might occur through greed and failing moral character, and can be used surreptitiously, maintaining the outward appearance of peace while softening up the opponent. Therefore, asymmetric warfare encompasses a wide scope of theory, experience, conjecture and definition, the implicit premise is that it deals with the unknown, with the surprise in terms of ends, ways and means. 


\section{REFERENCES}

Chinyamakobvu, Emmanuel. 2011. The Farm on Their Land. Bloomington: Author House.

Crothers, Lane; and Charles Lockhart (eds.). 2000. Culture and Politics: A Reader. New York: St. Martins Press.

Fagan, G. Honor; and Ronaldo Munck. 2009. Globalization and Security: Social and Cultural Aspects. Santa Barbara: Greenwood Publishing Group.

Fox, Jonathan. 2001. "Clash of Civilizations or Clash of Religions - Which is a more Important Determinant of Ethics Conflict?" Ethnicities, 1 (3): 295-320.

Hatem, Mervat Fayez. 2006. "In the eye of the storm: Islamic Societies and Muslim Women in Globalization Discourses". Comparative Studies of South Asia, Africa and the Middle East, 26 (1): 22-35.

Hess, Kären Matison; and Christine Hess Orthmann. 2012. Introduction to Law Enforcement and Criminal Justice. Independence: Cengage Learning.

Huntington, Samuel Phillips. 1993. "The Clash of Civilizations?". Foreign Affairs 72 (3): 22-28.

Huntington, Samuel Phillips. 2006. "The Clash of Civilizations?". In Twentieth

Century Political Theory: A Reader, edited by Stephen Eric Bronner, 439-456. New York: Routledge.

Huntington, Samuel Phillips. 2007. The Clash of Civilizations and the Remaking of World Order. New York: Simon and Schuster Paperbacks.

Kennedy, John Fitzgerald. 1962. "Remarks to the Graduating Class of the US Military Academy West Point". Speech made at New York, U.S., June.

Messinger, Gary S. 2011. The Battle for the Mind: War and Peace in the Era of Mass Communication. Amherst and Boston: University of Massachusetts Press.

Morgenthau, Hans Joachim. 1954. Politics among Nations: The Struggle for Power and Peace. New York: Alfred Knopf.

Nematandani, Kirsten. 2012. "Welcome Address by Mr. Kirsten Nematandani, South African Football Association President". Speech made at the FIFA-Interpol-COSAFA Integrity Workshop, Johannesburg, South Africa, August. 
Nye, Jr., Joseph S. 2004. Soft Power: The Means to Success in World Politics. New York: Public Affairs.

Paul, Thahza Varkey (ed.). 2001. The India-Pakistan Conflict: An Enduring Rivalry. New York: Cambridge University Press.

Robertson, Roland. 2000. Globalisation: Social Theory and Global Culture. London: SAGE Publications.

Sartori, Giovanni. 2005. Parties and Party Systems: A Framework of Analysis. Colchester: ECPR Press.

Seethaler, Josef; Karmasin, Matthias; Melischek, Gabriele; and Romy Wöhlert (eds.). 2013. Selling War: The Role of the Mass Media in Hostile Conflict from World War to 'War on Terror'. Chicago: The University of Chicago Press.

Shils, Edward. 1955. "Security and Science Sacrificed to Loyalty". Bulletin of the Atomic Scientists, XI (4) - Special Issue, April.

Smith, Charles Robinson. 2004. Deception: How Clinton Sold America Out to the Chinese Military. Columbus: The Pine Lake Media Group.

Stroilov, Pavel. 2011. Behind the Desert Storm: A Secret Archive Stolen from the Kremlin that Sheds New Light on the Arab Revolution in the Middle East. Chicago: Price World Publishing.

Tzu, Sun. 2003. The Art of War: Complete Text and Commentaries. Boston: Shambhala Publications.

Ulusoy, Hasan. 2004. "The Importance of Identity Building in Avoiding The Clash of Civilisations in The Age of Globalisation (With Some Reflections On Turkey-EU Relations)". SAM - Centre for Strategic Research. Available at: <http://sam.gov.tr/swpcontent/uploads/2012/01/Hasan-Ulusoy4.pdf $>$. Accessed March 30, 2013. 


\section{ABSTRACT}

This article offers an asymmetric warfare analytic conception through suggesting that asymmetric threats should be viewed in terms of the battle for the minds. With reference to the knowledge of asymmetric struggle, its patterns, conflict between civilisation and its nature in torn countries, clash of civilisation and its challenges, terrorism and insurgents, this work presents examples from the international level with the main thematic focus on Zimbabwe. The article suggests that there is a high level of asymmetric warfare ignorance among many and that asymmetric threats serve elite's national economic interests. It also suggests possibilities of protection or planning against an asymmetrical attack, bearing in mind that asymmetric warfare is a war of ideas where the center of gravity lies in the hearts and minds of the people.

\section{KEYWORDS}

Asymmetric Warfare; Civilisation; Interdependence; Globalization; Culture. 